\section{Training in practice}

SIR,-General practice is in the process of fundamental change-a painful, difficult and exciting period but essential if our discipline is to move forward. Your leading article on "Training in practice" (23 October, p 959) has initiated an impressive debate and $\mathrm{Dr}$ Cyril Hart (27 November, p 1321) raises new issues. $\mathrm{He}$ is "tempted to inquire from what source the Nuffield organisers received their own training and what are their credentials for setting themselves up on the apex of this impressive pyramid ... [and] how much contact those at the top have managed to maintain with the patients of their own practices." The nub of his complaint seems to be: what does the organiser of the Nuffield course know of the rough and tumble of general practice as the rest of us live it ? How well does he know his patients? How much time can he give to general practice?

It so happens that a quirk of mine is that I believe a most helpful assessment of my own standard of practice is to sit with a respected colleague during one of his normal surgeries. Being detached from the consultation is an important aspect for personal reflection. Since my relatively recent arrival in the United Kingdom I have been given the privilege of sitting with a number of senior colleagues, one of whom is the Nuffield organiser, Dr Paul Freeling. I am amazed how much I have been able to learn from these sessions, but none more so than that particular half-day. An interchange between us at the end of surgery has stayed in my mind: "You teach what you practise." "No, I practise what I teach." I can assure Dr Hart that these are generalists of the highest calibre and are essentially practical men in their art. The incredible thing is the number of surgeries that these men continue to do each week despite other commitmentsat least it certainly was so up to a few weeks ago. It seems to me we ought to give some thought to the enormous pressures that are put on these colleagues attempting to run general practices in tandem with general practice departments.

It is because of that episode in the Freeling practice that I am now a member of the current Nuffield course. Questions must be asked and answers gradually evolved, but if the Nuffield project stands for anything at all it is honesty in all that the term really means.

Dr Hart should continue to ask questions, but he would be wiser to think in terms of what are the real problems and perhaps he might find the real questions that have to be answered.

Roy GoulstoN

London SW9

SIR,-As a trainee general practitioner in the Oxford region, I was interested in your leading article on training in practice (23 October, p 959), which made its points with brevity and clarity. The same could not, unfortunately be said for all of the critical letters written in reply to it by doctors involved in general practice teaching (13 November, p 1191) Their quarrel appeared to be principally over the question whether it is feasible to make an objective assessment of training courses for course organisers. However, much of the correspondence was so densely obscured by jargon that it was not always possible to know what points were being made. At one place in his letter, Dr C J Leonard spoke of "aims, goals, and objectives" being "clearly defined in behavioural terms." Any difference between the words "aim," "goal," and "objective" can be of interest only to philosophers and the habitual attenders of courses such as those in the Nuffield Project. Indeed, as his letter progressed, Dr Leonard appeared to be transported into a kind of jargonistic ecstasy, speaking in tongues which were perhaps only to be interpreted by other behaviourist brethren.

This letter is not written with the trivial intention of criticising a colleague's literary style but out of a fear that the proponents of objective assessment may be spending so much of their time conferring together on how best to achieve their "aims, goals, and objectives" that they are losing touch with reality. Any doctor or medical student contemplating a career in general practice would surely be dismayed, on reading this correspondence, at the apparently baffling complexity of his chosen field.

While I am not qualified to comment on the value of "behaviourally orientated courses" for trainers, I do wonder whether objective assessment of vocational training, by behavioural or other means, is really necessary Surely the value of the training year is selfevident in that it gives the trainee the opportunity to find his feet in a new discipline and the time to discuss the management of patients with experienced colleagues. Is not the proper study of general practice general practice ?

\section{Patrick Rice-OxLey}

Witney, Oxon

SIR,-The contrast in your correspondence columns during the past month between those criticising and those defending training programmes for general practice points to a dichotomy that is going to increase unless the protagonists meet and discuss their difficulties.

I am sceptical of the validity of the new educational orthodoxy, with its emphasis on group methods followed by assessments that aim to study attitudinal changes. I share Dr Cyril Hart's cynicism (27 November, p 1321), and am pleased that an ex-trainee, Dr Margaret Thomson (p 1321), has similar doubts.

My feeling is that the time has come for some trainers and trainees to meet and talk about these problems. It is my hope to arrange such a meeting early next spring and I would welcome names and addresses of interested doctors so that details can be sent to them early in 1977 .

\section{K G DICKINSON}

Postgraduate Centre,

Dudley Road Hospital, Birmingham 18

\section{Compulsory admission}

SIR,-Why were so many psychiatrists and nurses ready to implement an "open door" (or at least a "revolving door") policy in mental hospitals when the 1959 Mental Health Act gave them opportunity ? Changes in a lifetime's habits do not usually occur so easily. I believe it was because so many of us had come to doubt the ethical justification for keeping people in custody under the rationalisation of treating them for illness. Doubtless ethics tends to raise questions rather than provide answers; but I am dismayed at how little the ethical implications of such problems as compulsory treatment, the care of child abusers, and the care of the mentally sick in secure units seem to affect discussion of them. Your leading article on compulsory admission (13 November, p 1157) almost seemed to imply that to express ethical concern at all was a mark of peculiar prejudice. A leading article in the Lancet ${ }^{1}$ stated baldly that "the doctor is manifestly an agent of the State." And at a recent conference of psychiatrists there was extensive discussion about the setting up of regional secure units without any mention of ethical implications at all. Yet all three examples raise issues the outcomes of which are going to affect not only patients but the doctors' (and nurses') understanding of their role and thus the public's understanding of the professions. Scientific objectivity may be ethically neutral; but the practice of medicine involves subjective factors and thus demands ethical reflection on what we do in our own interest as well as that of others.

To take secure units as an illustration: accepting that they are necessary, we need to remind ourselves of the corrupting effect that working in them may have on their staff. Custodial practices were certainly corrupting in old-style mental hospitals; and the uncovering of such corruption-sometimes in unexpected places-was one of the saddest experiences of those of us who were present at the opening of doors which were previously shut. And by corruption I mean the degradation of personality indicated by the unthinking inhumanity-not the deliberate wickednessthat staff were capable of displaying to those over whom they had power.

Doctors seem to be accepting more and more responsibilities as agents of social control which conflict with their responsibility for the health of their patients. Maybe most of us learn to tolerate the ambiguities of our role; but whether we do so by increasing or decreasing our sensitivity is open to doubt. We should at least face openly, and try to clarify, the problems involved-for the benefit of the nurses and others we train to care and then expect to behave as warders as well as for ourselves.

Hay on Wye,

' Lancet, 1976, 2, 775.

JAMES MATHERS

\section{Facilities for treatment of chronic renal} failure

SIR,-I am sure that your readers are as gravely concerned as I am about the present lack of facilities for patients in chronic renal failure and the shortage of cadaver kidneys for transplantation, which is causing the unnecessary death of many hundreds of our patients each year.

Regarding the first problem, in which money or the lack of it plays such a vital part, it would seem to me that some of the millions of pounds which are at the moment wasted on the prescribing of unnecessary tranquillisers and antidepressants, amounting to some $£ 20 \mathrm{~m}$ per annum, could be more gainfully used if general practitioners were to restrict the prescribing of these two types of drug.

Short-term dialysis, which is being widely used on the Continent, enabling two patients to undergo treatment using the same facilities 